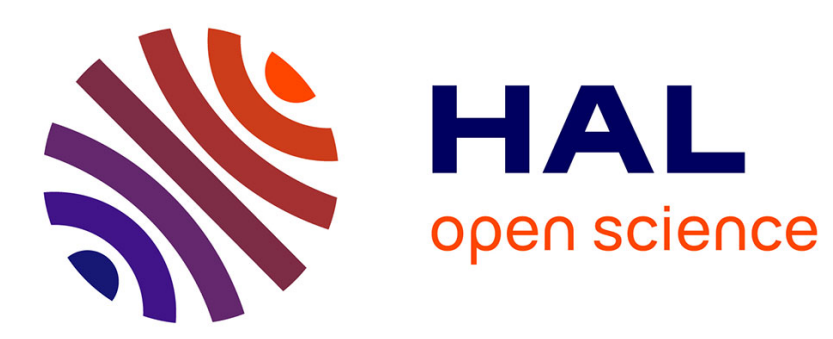

\title{
Energy Harvesting for Battery-Free Wireless Sensors Network Embedded in a Reinforced Concrete Beam
}

Alassane Sidibe, Gael Loubet, Alexandru Takacs, Daniela Dragomirescu

\section{To cite this version:}

Alassane Sidibe, Gael Loubet, Alexandru Takacs, Daniela Dragomirescu. Energy Harvesting for Battery-Free Wireless Sensors Network Embedded in a Reinforced Concrete Beam. 50th European Microwave Conference (EuMC 2020), Jan 2021, Utrecht, Netherlands. pp.702-705, 10.23919/EuMC48046.2021.9338186 . hal-03540600

\section{HAL Id: hal-03540600 \\ https://hal.laas.fr/hal-03540600}

Submitted on 24 Jan 2022

HAL is a multi-disciplinary open access archive for the deposit and dissemination of scientific research documents, whether they are published or not. The documents may come from teaching and research institutions in France or abroad, or from public or private research centers.
L'archive ouverte pluridisciplinaire HAL, est destinée au dépôt et à la diffusion de documents scientifiques de niveau recherche, publiés ou non, émanant des établissements d'enseignement et de recherche français ou étrangers, des laboratoires publics ou privés.

$$
\text { Copyright }
$$




\title{
Energy Harvesting for Battery-Free Wireless Sensors Network Embedded in a Reinforced Concrete Beam
}

\author{
Alassane Sidibe $^{\# 1}$, Gaël Loubet ${ }^{\# 2}$, Alexandru Takacs ${ }^{\# 3}$, Daniela Dragomirescu ${ }^{\# 4}$ \\ ${ }^{\#}$ LAAS-CNRS, Université de Toulouse, INSA, CNRS, UPS, F-31400, Toulouse, France \\ 1'alassane.sidibe@laas.fr, ${ }^{2}$ gael.loubet@laas.fr, ${ }^{3}$ alexandru.takacs@laas.fr, ${ }^{4}$ daniela.dragomirescu@laas.fr
}

\begin{abstract}
This paper deals with the design and the characterization of a compact and efficient rectenna, as well as the practical implementation of a wireless sensors network embedded in a reinforced concrete beam. The wireless sensors are powered by using a far field wireless power transmission technique through a rectenna operating in the European ISM $868 \mathrm{MHz}$ frequency band. The proposed rectenna is based on a compact 3D T-match dipole antenna with a size of $56 \mathrm{~mm} \times 32 \mathrm{~mm} \times 8 \mathrm{~mm}\left(0.00035 \cdot \lambda^{3}\right)$ placed at $60 \mathrm{~mm}$ relative to the ground plane of the sensing node used as a reflector $(140 \mathrm{~mm} \times 90 \mathrm{~mm})$; and an optimized rectifier. This rectenna provides a maximum dc voltage of $2.8 \mathrm{~V}$ and a RFto-dc efficiency of $67 \%$ across a $10 \mathrm{k} \Omega$ load with an illuminating power density of $3.9 \mu \mathrm{W} / \mathrm{cm}^{2}$ at $868 \mathrm{MHz}$. Thus, once embedded in reinforced concrete, the rectenna exhibits a dc power of $212.83 \mu \mathrm{W}$ when a $+32 \mathrm{dBm}$ EIRP power source located at $170 \mathrm{~cm}(156 \mathrm{~cm}$ in air and $14 \mathrm{~cm}$ in reinforced concrete) is used. Experimental results validate the sensing nodes supply by wireless power transmission in reinforced concrete, which allows the collect and the LoRaWAN transmission of physical parameters (temperature and humidity).
\end{abstract}

Keywords - Energy Harvesting, Wireless Power Transmission, Rectenna, Wireless Sensor Networks.

\section{INTRODUCTION}

With the huge democratization of the use of connected and communicating objects for long term applications, conventional power supply methods are showing their limitations: primary batteries need to be changed periodically, secondary batteries need to be recharge; and capacitors and supercapacitors have very limited energy storage capacities. The harvesting of ambient energies (EH) could be a solution to increase the lifetime of objects but ambient sources are not always available. In the case of a Wireless Sensors Network (WSN) in harsh environments as embedded in Reinforced Concrete (RC) -thus fully inaccessible once deployed-, light, thermal or mechanical energy sources could be insufficient or non-existent to be used as main power supply [1]. In this context, the use of far field Radio Frequency (RF) Wireless Power Transfer (WPT) approach makes sense [2]. In this paper, we will introduce an innovative rectenna (rectifying antenna) specifically designed in order to scavenge RF energy generated by a dedicated source and supply a wireless sensing node embedded in a reinforced concrete beam.

In the past, many antenna and rectifier was proposed and connected separately to for a rectenna as presented in [3-4]. In this paper is proposed a single Printed Circuit Board (PCB) three-dimensional (3D) rectenna allowing to reach a efficiency up to $67 \%$.This rectenna is tuned to work in the European Industrial, Scientific and Medical (ISM) $868 \mathrm{MHz}$ frequency band, is ultra-compact (56 $\mathrm{mm} \times 32 \mathrm{~mm} \times 8 \mathrm{~mm}$, only of $0.00035 \cdot \lambda^{3}$ ) In the following part, the targeted application: a communicating reinforced concrete made of an embedded battery-free WSN; and its implementation are introduced. Then, the design and the characterization of the manufactured ultracompact and efficient rectenna are developed. Finally, some tests and results of the use of the full system are presented as a full proof-of-concept never presented before in literature.

\section{WIRELESS POWER TRANSMISSION SYSTEM}

The smart wireless system presented in Fig. 1 is proposed in this paper. The aim is to wirelessly power a sensor node through a WPT interface including a rectenna in order to transmit data through LoRaWAN (Long Range Wide-Area Network) frames to a gateway [5]. From an electromagnetic (EM) waves radiated by a dedicated RF source, the rectenna transfers the harvested energy to a power management unit (PMU) (Texas Instruments bq25504) which stores this latter in a 22-mF supercapacitor (AVX BZ01CA223ZSB). Once enough energy is available (defined by an activation threshold of $5.25 \mathrm{~V}$ ), this one is used to supply the active part through a dc-to-dc regulator (Texas Instruments TPS6303x). The supercapacitor is discharged until a deactivation threshold of $2.30 \mathrm{~V}$. The active part is composed of a LoRaWAN communication module (Murata CMWX1ZZABZ-091) embedding a microcontroller unit (MCU) and a LoRa transmitter; and a temperature and humidity sensor (Texas Instruments HDC2010).

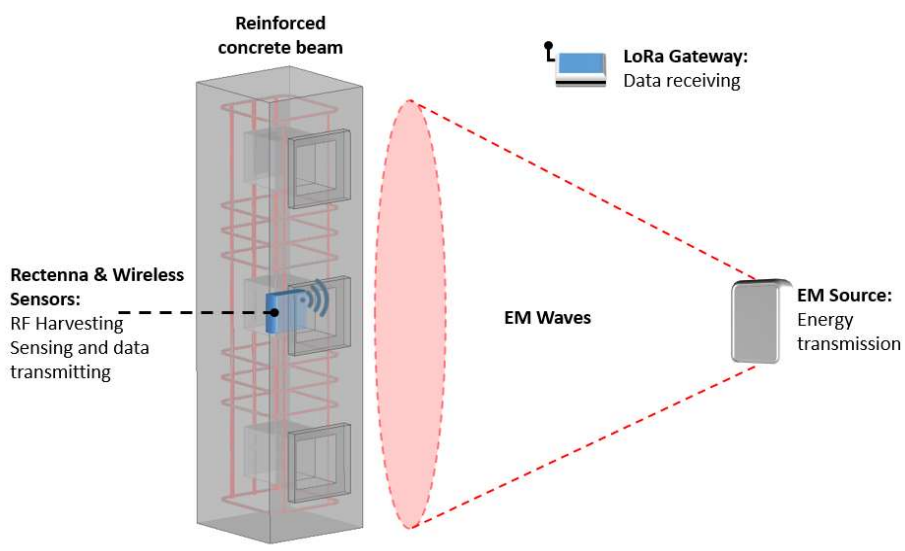

Figure 1. Schematic diagram of the targeted application. 
For each discharge of the supercapacitor, the MCU is started and initialized, a temperature and humidity measurement is achieved and a LoRaWAN frame with the collected data is transmitted.

\section{RECTENNA: Design, Simulation AND MEASUREMENT}

All the substrates used in this work are FR4 (thickness: 0.8 $\mathrm{mm}, \varepsilon_{r}: 4.3$ and $\left.\tan \delta: 0.02\right)$. The metallization is a thin layer of cooper of $35 \mu \mathrm{m}$. Simulations of the rectifier and the proposed antennas were carried out with Keysight Advanced Design System (ADS) and Ansys HFSS software, respectively.

\section{A. Rectifier design}

In this section, the conception of an optimized rectifier for a $10 \mathrm{k} \Omega$ load (which emulates the input impedance of the bq25504 [6]) and operating in the European ISM $868 \mathrm{MHz}$ frequency band is described. It consists of a doubler rectifier composed by a series pair of Schottky diodes (Skyworks SMS7630_005LF) [7]. The rectifier circuit is designed in coupled microstrip transmission lines. An LC matching network was designed and optimized. It is composed by a wirewound SMD inductor (Murata series LQW15AN - 33nH) serially connected and a shunt SMD capacitor (Murata series GRM15 - 4pF). For accurate simulation results, the Murata libraries, the spice model of the diodes and the parasitic model of the SOT-23 plastic diode package [8] were included in ADS simulation. More details about the rectifier design and experimental results are presented in [9].

\section{B. Antennas design and measurement}

Two antennas, namely DA for the 3D dipole antenna and DARP for the DA with a $14 \mathrm{~cm} \times 9 \mathrm{~cm}$ rectangular reflector plane (RP) are presented Fig. 2. The DA is composed of a planar dipole with a short circuit stub commonly known as T-match antenna [10]. As the dimensions of a typical dipole antenna at $868 \mathrm{MHz}$ are important, we reduced in this work the size of the dipole antenna by connecting vertically two short metallic arms (32 $\mathrm{mm} \times 10 \mathrm{~mm})$. Theses induce a capacitive effect and downshift the resonant frequency of the antenna. The geometries of DA are summarized in Fig. 2.

Knowing that the rectenna will be implemented with the sensing node, its grounded bottom side was considered as a reflector plane.

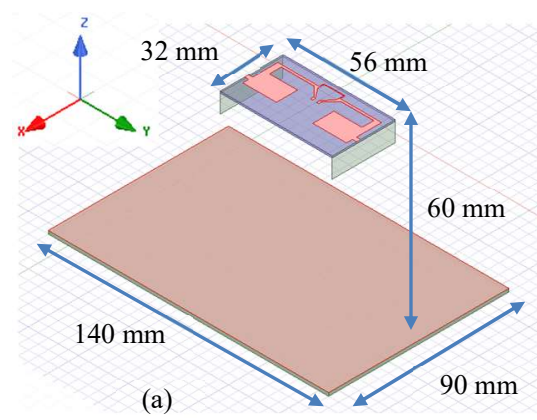

(b)

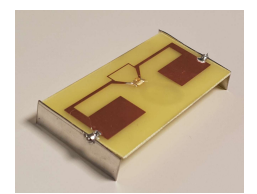

(c)

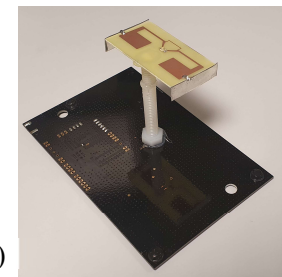

Figure 2. (a) Simulation model and geometries of the DARP antenna; (b) Manufactured DA antenna; (c) Manufactured DARP antenna.

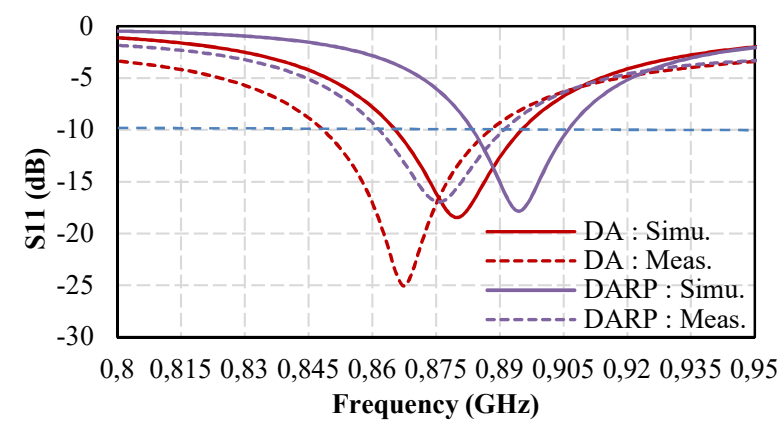

Figure 3. Comparison of the simulated and measured reflection coefficient of DA and DARP antennas.

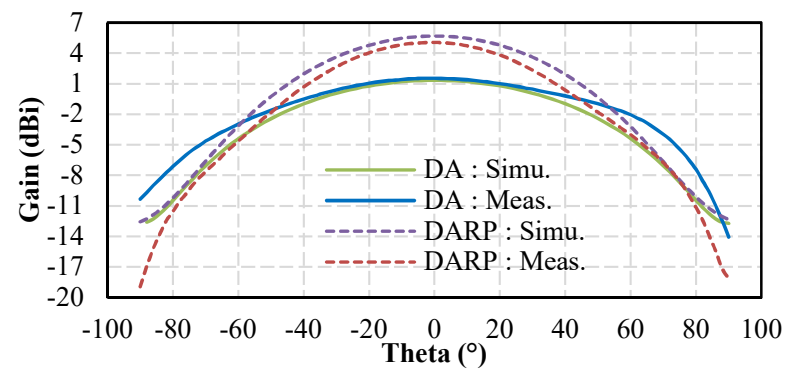

Figure 4. Simulated and measured radiation patterns (gain in $\mathrm{dBi}$ ) of the DA and DARP antennas in the E-plane at $868 \mathrm{MHz}$.

So that, it will increase the maximum gain of DA and thus the harvested power by the rectenna but reduce the beamwidth. Additional simulations were performed in order to verify the impedance matching of DARP and the optimal distance of DA from the RP. The largest side of the RP is placed in the direction parallel to the co-polarization plane of the antenna at a distance of $6 \mathrm{~cm}$ to focus the maximum gain in a single E-plane lobe and reduce the backlobe. Moreover, the width of the metallic arms was tuned to $8 \mathrm{~mm}$ (instead of $10 \mathrm{~mm}$ for DA). From the S11 plots in Fig. 3 the two different antennas are well matched as expected in simulation with a fabrication tolerance (imperfect shape of the metallic arms and connection with the planar dipole) which induces a down-shift of $15 \mathrm{MHz}$. As presented in Fig. 4, the measured gain in the E-plane for DA is $+1.54 \mathrm{dBi}$ and +5 $\mathrm{dBi}$ close to the simulated gain of $+5.68 \mathrm{dBi}$ for DARP.

\section{Rectenna measurements with and without reflector}

A rectenna with the DA antenna (R1) and a second connected with a nylon stem to the sensing node (R2) were finally prototyped. The experimental setup in an anechoic chamber (as presented in [4]) is composed of a patch antenna (gain $\mathrm{G}_{\mathrm{t}}=+9.4 \mathrm{dBi}$ ) connected to a $\mathrm{RF}$ signal generator (Anristu MG3694B) which injects a RF power $\mathrm{P}_{t}$. The insertion losses introduced by the cable were subtracted in the following calculations. The rectenna under test (which consists of DARP (gain $\mathrm{G}_{\mathrm{r}}$ ) antenna and a rectifier) was placed at a distance $d$ of $1.5 \mathrm{~m}$ from the transmitting antenna in its far field region with a linear polarized E-field. Then, a multimeter connected to the rectenna output measures the harvested dc voltage across the load. The setup is automatized by using a homemade data acquisition interface implemented in LabVIEW.

The performed measurements depicted in Fig. 5 show that the rectenna is well efficient at the desired frequency (868 
$\mathrm{MHz}$ ). It can harvest a maximum dc voltage of $1.9 \mathrm{~V}$ and $2.8 \mathrm{~V}$ for R1 and R2, respectively.

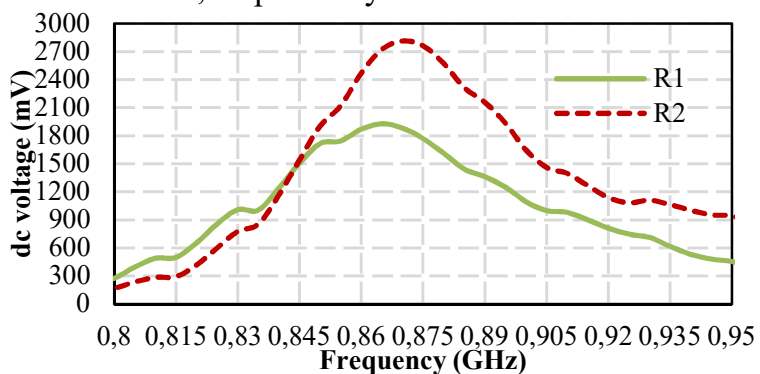

Figure 5. Measured de voltage for the two manufactured rectennas over the frequency in anechoic chamber at a power density of $3.4 \mu \mathrm{W} / \mathrm{cm}^{2}$.

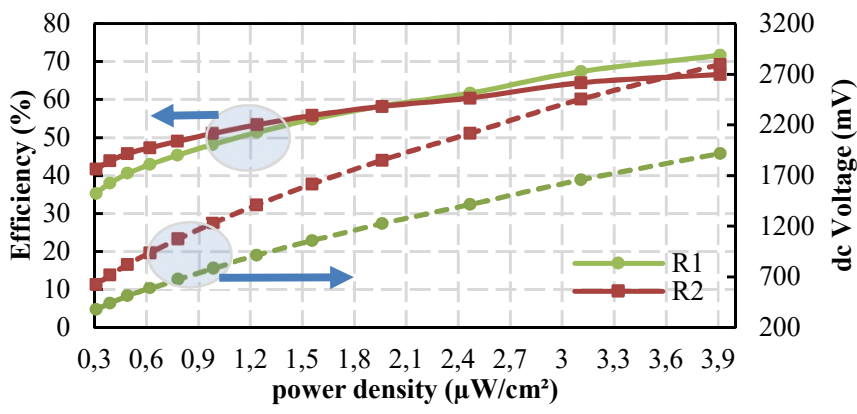

Figure 6. Computed RF to dc conversion efficiency (continuous line) and the measured dc voltage (dashed line) over the power densities at $868 \mathrm{MHz}$.

$$
\eta=\frac{P_{D C}}{P_{R F}}=\frac{4 \cdot \pi \cdot P_{D C}}{S \cdot G_{r} \cdot \lambda^{2}} \cdot 100 ; S=\frac{P_{t} \cdot G_{t}}{d^{2} \cdot 4 \cdot \pi}(1)
$$

The RF-to-dc efficiency versus power density is computed thanks to the formula (1) and is presented in Fig. 6. The measured dc voltage obtained for $\mathrm{R} 2$ increases by $1 \mathrm{~V}$ compared to $\mathrm{R} 1$ when the rectenna is illuminated by a power density of $3.9 \mu \mathrm{W} / \mathrm{cm}^{2}$. However, above $2 \mu \mathrm{W} / \mathrm{cm}^{2}$, R2 exhibits lower efficiency than for R1 due to the Schottky diodes saturation when receiving too much power (with a higher gain antenna). The maximum RF-to-dc conversion efficiency is about $71 \%$ for $\mathrm{R} 1$ and $67 \%$ for $\mathrm{R} 2$ for $\mathrm{S}=3.9 \mu \mathrm{W} / \mathrm{cm}^{2}$.

\section{BATTERY-LESS SySTEM PERFORMANCE MEASUREMENTS}

The interesting performances obtained by R2 allows embedding the full rectenna in a cavity of the reinforced concrete beam manufactured to perform experiments and whose dimensions are presented [3].

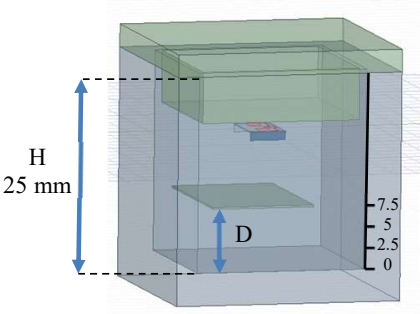

\begin{tabular}{|c|c|}
\hline $\mathbf{D}(\mathbf{c m})$ & dc power $(\boldsymbol{\mu W})$ \\
\hline $\mathbf{0}$ & 82.35 \\
\hline $\mathbf{2 . 5}$ & 175.84 \\
\hline $\mathbf{5}$ & 219.83 \\
\hline $\mathbf{7 . 5}$ & 56 \\
\hline
\end{tabular}

Figure 7. dc power as function of the position of the rectenna (R2) inside the covered concrete cavity (top green part is the cover).

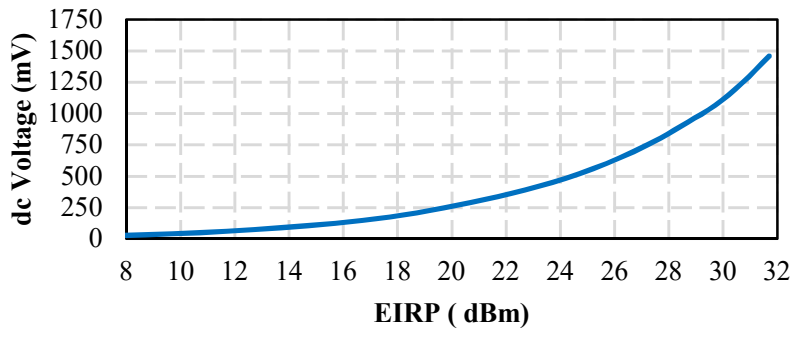

Figure 8. Harvested dc voltage of the DARP over the EIRP of the RF source positioned at $170 \mathrm{~cm}$ far away from the rectenna fully embedded in the covered concrete cavity at $868 \mathrm{MHz}$.

In this paper, $\mathrm{H}$ is the distance between the bottom side of the cavity and the top side of the uncovered concrete beam (25 $\mathrm{cm}$ ) and $\mathrm{D}$ the elevation position of the sensor node (R2) relative to the bottom side.

The optimal position of the rectenna placed inside the covered concrete cavity $(15 \mathrm{~cm} \times 15 \mathrm{~cm} \times 15 \mathrm{~cm})$ was experimentally verified. Thus, a characterization of $\mathrm{R} 2$ by measuring the harvested dc voltage across a $10 \mathrm{k} \Omega$ load was performed as a function of the rectenna position (fully embedded in the concrete beam) illuminated by a transmitting antenna (at a distance of $156 \mathrm{~cm}$ relative to the top of the concrete beam.). As seen in Fig.7, the maximum dc power obtained inside the cavity was obtained for $\mathrm{D}=5 \mathrm{~cm}$. In this position, the rectenna exhibits a maximum dc voltage of $1.46 \mathrm{~V}$ with $+32 \mathrm{dBm}$ EIRP power (Fig. 8) generated by the RF source positioned at $170 \mathrm{~cm}(156 \mathrm{~cm}$ in air and $14 \mathrm{~cm}$ in the concrete) far away from the rectenna embedded in the concrete. This optimal position was chosen for the next steps.

After having characterized the rectenna in the anechoic chamber and embedded in the covered concrete cavity, a full sensing node prototype was characterized. Then, the output of the rectenna was connected no more to the $10 \mathrm{k} \Omega$ load but to the input pins of sensing node as shown in Fig. 10 (b). In all experiments, a signal power generator connected to a patch antenna is used as the RF source with a transmitting EIRP power fixed at $+32 \mathrm{dBm}$ at $868 \mathrm{MHz}$. The voltage measurements were performed using a LeCroy WaveRunner 6100 oscilloscope. The operational behaviour of the sensing node and its functionality are fully described in [11].

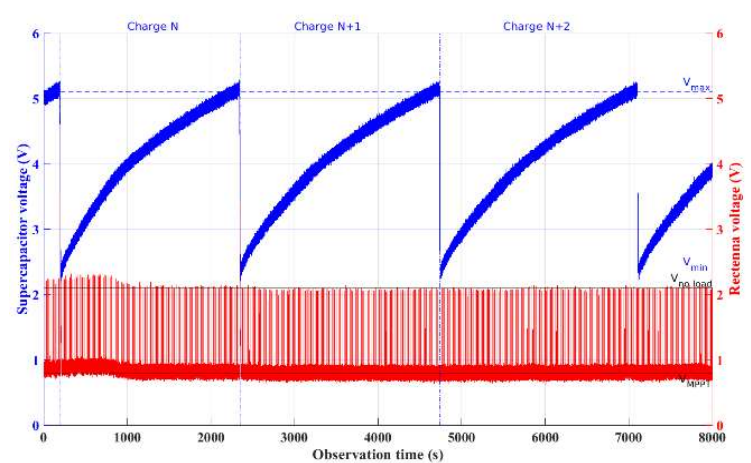

Figure 9. Voltage waveforms at the ports of the supercapacitor (blue upper curve) and rectenna output voltage (red lower curve) for a $+32 \mathrm{dBm}$ EIRP power. 


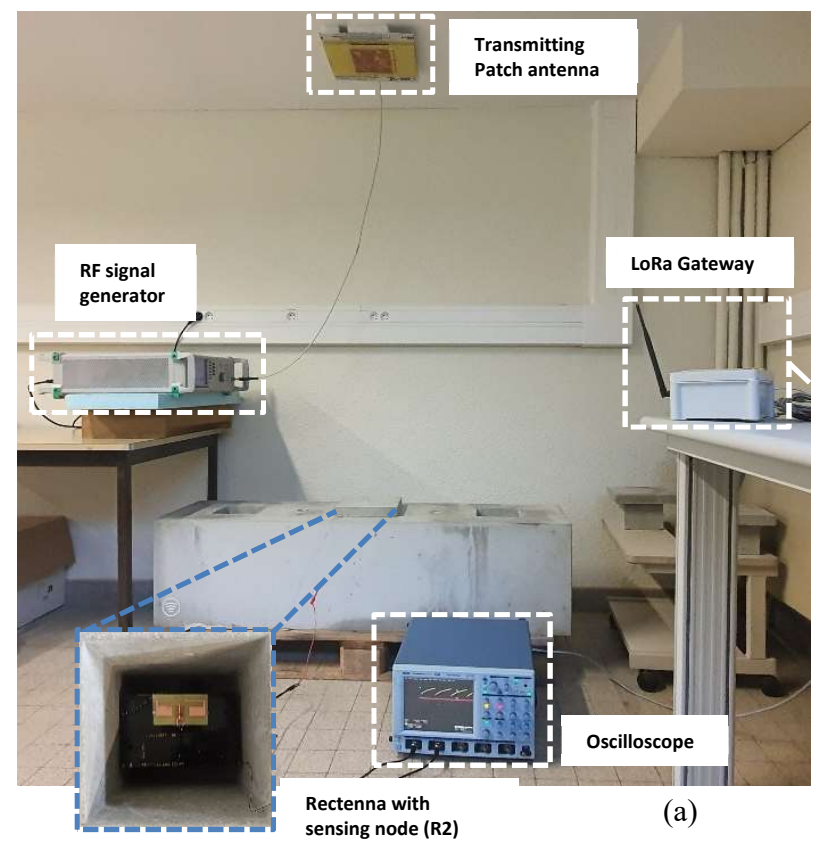

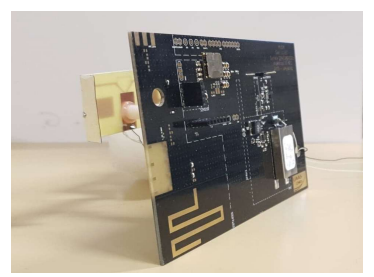

(b)

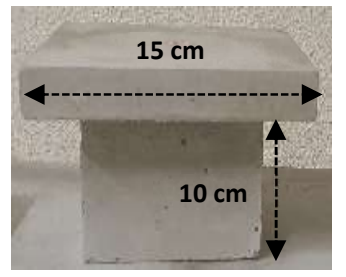

(c)

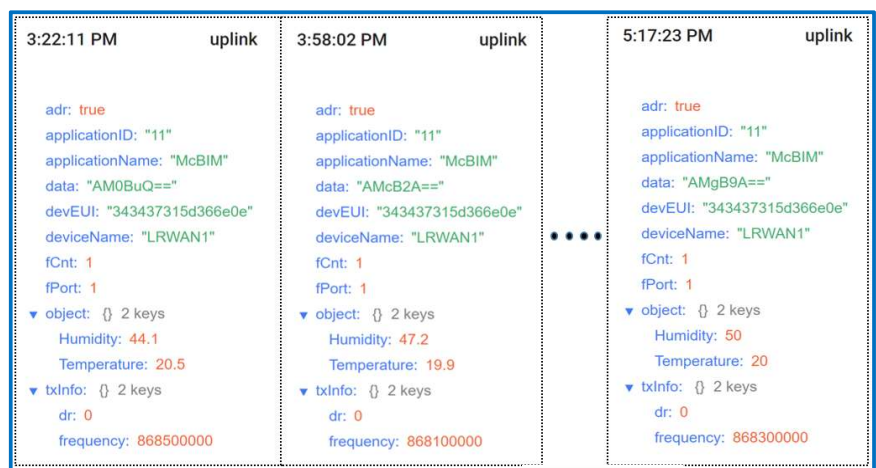

(d)

Figure 10. Experimental setup of WPT system (the rectenna R2 with the sensing node acting as a battery-free wireless sensor was placed inside the covered concrete cavity, the RF source and the LoRa gateway); (b) Bottom view of the sensing node connected to the rectenna; (c) The cover of the hole/cavity (sized $15 \mathrm{~cm} \times 15 \mathrm{~cm}$ x $15 \mathrm{~cm}$ ) where the rectenna was embedded; (d) Received data from the LoRa gateway.

As seen in Fig. 9, the PMU (bq25504) stores the available power provides by the rectenna until the voltage across the supercapacitor exceeds $5.25 \mathrm{~V}$ and then supplies the active components until the voltage goes down under $2.30 \mathrm{~V}$.

During each discharge a temperature and humidity measurement and a LoRaWAN frame transmission are achieved. According to Fig. 9 and Fig. 10 (d), nearly 36 minutes are needed for a complete charge of the supercapacitor and the transmission of the temperature and humidity data to a local LoRaWAN gateway.

\section{CONCLUSION}

For the first time, a wirelessly powered and battery-free LoRaWAN wireless sensing node fully embedded into a concrete beam was presented. Its RF energy harvesting system is composed by a compact $\left(0.00035 \cdot \lambda^{3}\right)$ and optimized rectenna. By using the grounded plane of the sensing node as a reflector, the gain of the antenna/rectenna increases from $+1.54 \mathrm{dBi}$ to +5 dBi. Thus, the rectenna exhibits an efficiency of $67 \%$ at 868 $\mathrm{MHz}$ for a power density of $3.9 \mu \mathrm{W} / \mathrm{cm}^{2}$. The sensing node embedded into reinforced concrete is able to collect and transmit temperature and humidity data though a LoRaWAN frame to a gateway each 36 minutes by harvesting the RF energy specifically generated by a RF source located at $170 \mathrm{~cm}$. Thus, this system is for SHM applications in the construction domain.

\section{ACKNOWLEDGMENT}

The authors would like to acknowledge all their partners in the ANR McBIM project [11], especially FINAO SAS/260SmartConnect for providing well defined use cases and the reinforced concrete beam.

\section{REFERENCES}

[1] B. Han, L. Zhang and J. Ou, Smart and Multifunctional Concrete Toward Sustainable Infrastructures, 1st ed., Singapore: Springer, 2017, pp. 379390.

[2] Cost Action IC1301 Team, "Europe and the Future for WPT: European Contributions to Wireless power Transfer Technology", IEEE Microwave Magazine, vol. 18, issue 4, pp. 56-87, June 2017.

[3] G. Loubet, A. Takacs, E. Gardner, A. De Luca, F. Udrea and Daniela Dragomirescu, "LoRaWAN Battery-Free Wireless Sensors Network Designed for Structural Health Monitoring in the Construction Domain", MDPI Sensors 19, March 2019.

[4] A. Takacs, A. Okba, H. Aubert, "Compact Planar Integrated Rectenna for Batteryless IoT Applications", 48 ${ }^{\text {th }}$ EuMW, Sept 2019

[5] LoRa Alliance Technical Committee. LoRaWAN 1.1 Specification; LoRa Alliance Technical Committee Beaverton, OR, USA, 2017 [Online]. Available: https://lora-alliance.org/sites/default/files/201804/lor awantm_specification_-v1.1.pdf (accessed on 12 February 2020).

[6] Texas Instrument - bq25504 Ultra-Low Power Boost Converter with Battery Management for Energy Harvesting Applications. [Online]. Available: http://www.ti.com/lit/ds/symlink/bq25504.pdf (accessed on 14 January 2019).

[7] Skyworks- Surface Mount Mixer and Detector Schottky Diodes (SMS7630-005LF) [Online]. Available: https://www.skyworksinc.com/-

/media/A36775836A4E4BA8A92104088692424F.ashx (accessed on 12 February 2020).

[8] Application note 1124, Linear Model for Diode Surface Mount Packages, http://www.hp.woodshot.com/hprfhelp/4_downld/lit/diodelit/an1124.pd f (Accessed 03 February 2020).

[9] A. Sidibe, A. Takacs, "Compact 3D Rectenna for Low-Power Wireless Transmission", URSI GASS, 2020 (Accepted).

[10] G. Zamora, S. Zuffanelli, F. Paredes, F. Martin and J. Bonache, "Design and Synthesis Methodology for UHF-RFID Tags Based on the T-Match Network," IEEE Transactions on Microwave Theory and Techniques, vol 61, Issue 2, pp. 4090-4098, December 2013.

[11] ANR-17-CE10-0014 McBIM project (Communicating Material at the disposal of the Building Information Modeling), http://www.agencenationale-recherche.fr/en/anr-

fundedproject/?tx lwmsuivibilan pi $\% 5 \mathrm{BCODE} \% 5 \mathrm{D}=\mathrm{ANR}-17-\mathrm{CE} 10$ 00 (accessed the 10 April 2019). 